Dicenda. Estudios de lengua y literatura españolas

ISSN-e: 1988-2556

https://dx.doi.org/10.5209/DICE.64999

\title{
Don Quijote de la Mancha y san Ignacio de Loyola en la reinterpretación de Miguel de Unamuno
}

\author{
Yasmina Mohamed Lozano ${ }^{1}$
}

Recibido: 24 de mayo de 2017 / Aceptado: 1 de junio de 2018

Resumen. Miguel de Unamuno comparó insistentemente a su Caballero de la Fe, don Quijote, con diversas figuras religiosas. No obstante, uno de los paralelismos sobre los que más insistió fue el del jesuita san Ignacio de Loyola. A su vez, nuestro autor varió de roles, presentádose la mayoría de veces como su profeta, encargado de predicar con la palabra e incluso el ejemplo la acción quijotesca. En otras ocasiones, llegaría compararse con don Quijote en momentos en los que previamente lo había equiparado ya al santo jesuita, creándose así otra indirecta autodivinización. En este artículo se pretende ofrecer una vinculación multidireccional entre el don Quijote unamuniano, san Ignacio, Pedro de Ribadeneyra - biógrafo del santo-y el mismo Unamuno.

Palabras clave: Unamuno; Loyola; paralelismos; cristianismo quijotesco.

\section{[en] Don Quixote de la Mancha and St. Ignatius of Loyola according to Miguel de Unamuno's reinterpretation}

\begin{abstract}
Miguel de Unamuno consistently compared his Knight of the Faith, don Quixote, with various religious figures. Nevertheless, one of the parallels on which he insisted most was the relationship with the Jesuit St. Ignatius of Loyola. In turn, our author played different roles, in most of the occasions, introducing him as his prophet responsible for preaching the quixotic action with the word and the example. At other times, he equaled don Quixote when he had previously equated the Jesuit saint, creating thus an indirect self-divination. This article intends to offer a multidirectional entailment between the Unamuno's don Quixote, St. Ignatius, Pedro de Ribadeneyra — saint's biographer — and Unamuno.
\end{abstract}

Keywords: Unamuno; Loyola; parallelism; quixotic Christianity.

Cómo citar: Mohamed Lozano, Y. (2019). Don Quijote de la Mancha y san Ignacio de Loyola en la reinterpretación de Miguel de Unamuno, en Dicenda. Estudios de Lengua y Literatura Españolas, 37, 163-183.

En este artículo trataremos de abarcar aquellos aspectos que resulten de especial interés en cuanto a la actitud del poliédrico rector de Salamanca, Miguel de Unamuno, respecto a las semejanzas halladas por él entre don Quijote de la Mancha y el jesuita san Ignacio de Loyola, especialmente manifestadas en su ensayo de 1905, Vida de

Facultad de Filosofía y Letras de la Universidad de Málaga

yasminam190@gmail.com 
Don Quijote y Sancho ${ }^{2}$; una obra que, más que la búsqueda de una interpretación erudita, consistió en una creación íntima y personal de valor literario en la que Unamuno volcó sus pensamientos sobre la conflictiva situación del momento y toda su ideología, pues, como cita Bucurenciu, él mismo llegó a afirmar: “escribo para pensar, porque pienso escribiendo o hablando" (Bucurenciu Birsan, 1977: 236).

Miguel de Unamuno se inscribe en el pensamiento romántico, caracterizado por la obsesión con el cristianismo, el nacionalismo y el afán por volver al Siglo de Oro, un retorno fundamentalmente en clave religiosa, un regreso al pasado cristiano alejado de todo materialismo; y es que, tras el conocido desastre del 98 y las derrotas militares en Cuba y Filipinas, la acentuada crisis política y existencial llegó a tambalear los valores de la época. Unamuno trató de regenerar el pueblo español dotándolo de una nueva fe, una fe ideal y nacional. Así, en lo referente al ámbito religioso, el ingenioso hidalgo manchego supondría, para nuestro escritor, la creación de una nueva rama de la creencia cristiana que bautizaría como quijotismo o cristianismo quijotesco. Un pretexto ante la situación nacional. Una religión para despertar al pueblo a la crítica social en la que Unamuno sería su Profeta, promoviendo con su ejemplo y palabra las enseñanzas del Caballero de la Triste Figura.

El rector de Salamanca, sin duda, se esforzó por encarnar en la figura de don Quijote un mito cristiano al que dar un carácter tan real como el de los creyentes que confían en la existencia de Jesucristo, uniendo como tres aspectos de una misma realidad —al igual que sucede con la Santísima Trinidad—, según menciona José Ferrater: "el espíritu español (o hispánico), el espíritu humano y el espíritu quijotesco" (Ferrater Mora, 1985: 93). Para ello, un recurso habitual sería el de establecer paralelismos entre su proclamado Cristo Hispánico, don Quijote, y otras figuras religiosas relevantes, como apóstoles, mártires, Jesucristo e incluso Dios; tratando así de exaltar como divinizable algo que Cervantes intentó plasmar en su obra como el reflejo de una tierra de defectos. Sin embargo, la más extensa de todas las comparaciones efectuadas por nuestro pensador fue la ligada con san Ignacio de Loyola.

Ya se ha indicado que "las lecturas españolas que dejan huella en la obra de Unamuno son sobre todo religiosas"(Montesinos, 1990: 27); no es de extrañar que, entre tantos libros de mística y ascética, hallara otra representación más de la religión española en la figura de don Quijote, a la que adherir - dos caballeros empeñados en la defensa de la fe cristiana, según su visión - la de san Ignacio. La Vida del que Unamuno proclamó insistentemente como Íñigo - a fin de reivindicar su nombre vascónico original, pues, según el mismo autor, "del Íñigo de Loyola han hecho un Ignacio de Roma, del héroe vasco un santón jesuítico" (VQS, p. 207) - constituyó para él un antecedente de lo que implantaría después en su biografía quijotesca, que quiso contemplar como una obra del espíritu católico castellano de carácter universal: "La vieja idea castellana castiza encarnó en una literatura y en otras obras no literarias, porque las de Íñigo de Loyola y Domingo de Guzmán, ¿no son acaso hijas del espíritu castellano casado con el catolicismo y universalizadas merced a este?" (Unamuno, 2007: 101).

Ya en noviembre de 1896 redactaría Unamuno una nota a pie de página en su ensayo "El Caballero de la Triste Figura", para insistir no solo en las semejanzas de actuación de ambos caballeros cristianos, sino también en las similitudes físicas existentes entre ellos, tomadas a partir de criterios de autoridad, como serían las

En adelante citada como VQS. 
ilustraciones de Luis de Madrazo en las que representó al ingenioso hidalgo ante la princesa Micomicona y el afamado retrato que Sánchez Coello hizo de san Ignacio (Unamuno, 2007: 275). Así, podrá observarse en la lectura de algunos textos unamunianos, y especialmente en la Vida de Don Quijote y Sancho, cómo este lo identificó con el antecesor de don Quijote, sometiendo siempre la supeditación de ambas figuras a su particular visión, no a los personajes originales de Cervantes y Ribadeneyra: "Yo veo semejanzas entre la vida de [...] mi don Quijote y la de mi san Ignacio; y de lo demás se me da un bledo"(275).

A pesar de su admiración por el fundador de la Compañía de Jesús, la actitud de Unamuno hacia los jesuitas y sus costumbres fue crítica. Ya se pronunció a este respecto en "Sobre la erudición y la crítica" (1905): "San Ignacio de Loyola, mi paisano - por el que siento más admiración que todos los jesuitas juntos-" (Unamuno, 2007: 800). Y con la publicación de su artículo "La Educación Jesuítica" (1912) dejó constancia de que la Compañía jamás mostró respeto hacia el Caballero de la Fe y fundador del cristianismo quijotesco, basándose en que cierto jesuita le confesó que, durante una fiesta, los novicios quemaron en una hoguera un ejemplar del Quijote mientras saltaban sobre sus llamas (Unamuno, 1921: 234). Unamuno acusó a la Compañía de Jesús de no entender ni la importancia del sentimiento quijotesco del ridículo ni el sacrificio de perseverar en el esfuerzo por hacer lo correcto, pese a las humillaciones y derrotas consecuentes. Por lo que a la concepción unamuniana respecta, la figura del fundador de la Compañía no tuvo relación con el papel desempeñado por sus miembros.

Según Adolfo Alas, Unamuno tenía previsto escribir una vida de san Ignacio de Loyola como reflejo del alma del pueblo vasco; sin embargo, no llegó a hacerlo y, en su defecto, "vertió en la Vida de Don Quijote y Sancho la esencia del San Ignacio que llevaba tan dentro de sí" (Alas, 1941: 64), pues sentía una estrecha relación de hermandad con el jesuita, de quien era paisano. Y es que "para Unamuno, San Ignacio es el Quijote de la Iglesia, el hidalgo que se deja enloquecer por la mayor gloria de Dios. Unamuno vibraba no con el objeto de la pasión de san Ignacio, sino con la fuerza volcánica del apasionamiento" (Iparraguirre y Dalmases, 1982: 37). Se trata de un paralelismo cargado de genialidad y sugestión que, finalmente, se reduce a lo que podría llamarse una interpretación de "las de Unamuno: fulguraciones sentimentales, nacidas al calor de una idea sentida con avasalladora vivencia" (37). De manera que el vínculo existente entre el pensador bilbaíno y el santo no tendría lugar con un Ignacio de Loyola real e histórico, sino con el que él había adaptado para sí, tal y como sucede con don Quijote. Así lo reflejó Nemesio González Caminero, agradecido de que nuestro autor no llegase a biografiar al santo jesuita:

A buen seguro que no hemos perdido nada con que Unamuno dejara irrealizada una biografía sobre san Ignacio. Aparte de las abiertas falsedades y tergiversaciones que infaliblemente la hubieran manchado, sería toda una mera interpretación novelística, inconsciente e inútil (González Caminero, 1948: 369).

La insistente relación entre Ignacio de Loyola y don Quijote de la Mancha no fue una idea original del rector de Salamanca. La repercusión de la figura del santo jesuita alcanzó a escritores como Quevedo, Lope de Vega, Góngora, Calderón de la Barca o el propio Cervantes; pero no fue hasta finales del siglo XIX cuando comenzó a forjarse la concepción del "san Ignacio “"histórico"” (Iparraguirre y Dalmases, 1982: 19). En este 
aspecto, Unamuno trató, una vez más, de restar mérito a Cervantes - y a estudiosos predecesores suyos - , pretendiendo adjudicarse el descubrimiento de las relaciones entre don Quijote y san Ignacio sobre la hipótesis de que el vínculo del personaje histórico vasco lo estableció en torno a su propio hidalgo manchego, no al cervantino. En ello insistiría en su artículo "Sobre la erudición y la crítica" (1905):

Constantemente, al comentar el Quijote, dejo a Cervantes fuera y no me interesa ni poco ni mucho lo que este buen hidalgo pensara al escribir su obra, ni lo que quiso decir en ella, si es que quiso decir algo más de lo que a las claras y a primera vista se lee allí. No, no es eso. Yo veo semejanzas entre la vida de don Quijote y la de san Ignacio, por lo menos entre la de mi don Quijote y la de mi san Ignacio; y de lo demás se me da un bledo, porque no he pretendido hacer una obra de erudición ni de exégesis esotérica, ni ese es el camino (Unamuno, 2007: 806).

A pesar de que Unamuno no fue el único y mucho menos el primero en establecer tales semejanzas, como apunta Luis Iglesias al enumerar otros autores que ya habían tratado dichas semejanzas entre Íñigo de Loyola y don Quijote(Iglesias Ortega, 1990: 857-858), sin duda, nuestro autor se adueñó bastante bien de las mismas y asentó pertinazmente una serie de coincidencias, especialmente en su ensayo Vida de Don Quijote y Sancho, obviando del todo cualquier similitud ligada a métodos narrativos.

El primer y esencial paralelismo entre Íñigo de Loyola y don Quijote de la Mancha fue, sin duda, el afán por la lectura de caballeros cristianos a los que imitar. La misma Vida de San Ignacio redactada por el padre Pedro Ribadeneyra presentaba al santo como un hombre "muy curioso y amigo de leer libros profanos de caballerías" (Ribadeneyra, 1863: 25), lo cual no es de extrañar considerando que, por esa época, "el éxito de la novela de caballerías es éxito de una producción de masa" (Chevalier, 1976: 69). Sin embargo, ya desde el siglo anterior, estas lecturas se vinculaban con círculos cortesanos y, por aquel entonces, tampoco faltaron "los anatemas que contra ella fulminaron los moralistas, erasmistas y no erasmistas, del siglo XVI" (65). Así, no sorprende que Ribadeneyra se alegrase de que san Ignacio no encontrara estos libros: "quiso Dios que no hubiese ninguno en casa, sino otros de cosas espirituales, que le ofrecieron; los cuales él aceptó, más por entretenerse en ellos que no por gusto y devoción" (Ribadeneyra, 1863: 26). Por tanto, al igual que a don Quijote, le tentaban los libros de caballerías, que en su lectura quedaron, frente a la de Alonso Quijano, desplazados por los libros espirituales, de modo que los cercanos de Ignacio "vinieron a entender que estaba tocado de Dios y que no era el que solía ser" (32), una transformación similar a la que sufrió Alonso Quijano. Íñigo de Loyola y don Quijote idealizaron el mundo enfrentando la oposición de su entorno.

Unamuno, por ello, insistiría en resaltar la tenaz actitud del devoto vasco en su doble imitación tanto de caballeros como de santos. De hecho, Emilio Castelar - que ya había establecido tal comparación en 1883 - igualó la falta de cordura de ambos personajes cuando afirmaba, refiriéndose a san Ignacio, que el "remordimiento de sus pecados antiguos le nublaba la mente y le hacía perder casi el juicio" (Castelar, 1883: 99).

La Vida de don Quijote y Sancho aprecia numerosos parecidos entre las dos figuras. Ya en el capítulo I de la novela cervantina, Unamuno comparó los temperamentos de ambas figuras: coléricos y serios, aficionados a las lecturas de unos libros 
de caballerías que, antes o después, les serían negados. "Y es natural que Loyola fuese del mismo temperamento que don Quijote, porque había de ser capitán de una milicia y su arte, arte militar" (VQS, p. 160). Más adelante nuestro autor volvería a referirse a la descripción física del santo expuesta por su historiador, en el capítulo XVIII del Libro IV de la Vida de San Ignacio, para deducir por sí mismo que, si bien el caballero vasco tenía una frente ancha y calva, señales de ingenio militar según estudios del doctor Huarte, don Quijote también había de ser calvo y de frente ancha (VQS, p. 160).

De nuevo, en el capítulo II de la novela de Cervantes, Unamuno tuvo en consideración la figura de Ignacio de Loyola respecto al momento en que don Quijote abandonó humildemente su hogar, siendo honrado y fiel a sus ideales y a las leyes impuestas por la caballería; actitud que haría a nuestro autor evocar la obra de Ribadeneyra sobre la Vida del bienaventurado Padre Ignacio de Loyola; la cual, según inventa el propio pensador bilbaíno:

[...] era una de las que figuraban en la librería de don Quijote, que la leyó, y una de las que en el escrutinio que de tal librería hicieron el cura y el barbero, fue indebidamente al fuego del corral, por no haber ellos reparado en ella, que a haberla descubierto habríala el cura respetado y puesto sobre su cabeza. Y de que no reparó en ella, es buena prueba el que Cervantes no la cita (VQS, p. 168).

Según Unamuno, el hidalgo fue un acérrimo creyente que actuó de manera similar al fundador de los jesuitas, sin planificar ni programar decisiones, dejándose llevar por el azar (VQS, p. 173). Es decir, que don Quijote internalizó "como uno de los libros de caballerías que con tanta pasión leía, la Vida de San Ignacio" (García Mateo, 1999: 131). Por todo esto, no es de extrañar que se hallen tantas semejanzas entre ambos personajes, "no por casualidad, sino porque don Quijote conocía bien la persona y la obra de san Ignacio y la había hecho suya, consciente o inconscientemente"(131).

Sobre el capítulo III del Quijote, la semejanza surge ante el hecho de que ambos se enfrentaron a las asperezas de la vida y, en su momento, Ignacio de Loyola, "como caballero novel de Cristo, con espiritual representación [de] aquel hecho caballeroso" decidió ir a Montserrat a velar sus armas (Ribadeneyra, 1863: 41), a la par que don Quijote las custodió "en un corral grande que a un lado de la venta estaba" (Cervantes, 2008, I: 130) a fin de consagrarse ambos como caballeros de la fe.

En el cuarto capítulo, don Quijote evidenció lo que ya anticipaba Unamuno sobre su fe incuestionable en los designios divinos: se dejó llevar por "el camino que a Rocinante le placía, pues todos ellos llevan a la eternidad de la fama" (VQS, p. 182); lo cual le hizo reconstruir el capítulo III del Libro I de la Vida de Íñigo de Loyola, en que este se encontró con un musulmán que renegó de la pureza de la Virgen María afirmando que, tras dar a luz, dejó de ser virgen. Entonces el fundador de los jesuitas dudó sobre si había o no de apuñalarlo, decidiendo que fuese el caballo el que decidiese si seguirlo y acabar con él, o no (Ribadeneyra, 1863: 37-38). De igual modo, con esa confianza en la elección de sus monturas, se encomendaron al instinto animal propio de la caballería, que es el que depende de la voluntad de Dios. Por ello, cuando don Quijote se encontró al león, en la Segunda Parte de su novela, este entendió que se lo había enviado Dios (Cervantes, 2008, II: 166). También así, en otra ocasión, fue san Ignacio quien se afirmó capaz de surcar los mares sin llevar vela ni remos si 
el Papa lo dictaminase (Ribadeneyra, 1863: 561). Y es que ya lo sentenció Unamuno en el comentario al capítulo XXIX de la Segunda Parte del Quijote dirigiéndose a su Cristo Hispánico:

Tu hazaña, tu verdadera hazaña, la que hará valer tu vida, no será acaso la que vayas tú a buscar, sino la que venga a buscarte, y jay de los que van en busca de la dicha mientras está ella llamando a las puertas de su casa! Por algo se dijo lo de que las más grandes obras son obras de circunstancia (VQS, p. 391).

Habría que volver al séptimo capítulo cervantino en que la sobrina del hidalgo suplicaba a este que no efectuase su segunda salida. "También para disuadir a Íñigo de Loyola de que saliese a buscar aventuras en Cristo, acudió su hermano mayor, Martín García de Loyola" (VQS, p. 193), explicaría Unamuno citando el capítulo III del Libro I de la Vida de Ribadeneyra y añadiendo que, sin duda, san Ignacio hubo de responder "que él miraba por sí y se acordaría que había nacido de buenos, y salió de caballero andante" (VQS, p. 193).

Ambos marcharon acompañados. San Ignacio de Loyola partió con criados a los que dejaría regresar más tarde (Ribadeneyra, 1863: 36) y don Quijote se fue con Sancho Panza, su recién adquirido escudero. Ante ese segundo caso, Unamuno defiende a ambos de las acusaciones de algunos lectores que vieron diversas ambiciones: ambición de riquezas en el escudero y de fama en el amo: "¿Y quién se esquiva de la codicia y quién de la ambición? Temíalas İ̃nigo de Loyola" (VQS, p. 195), pues según el capítulo XV del Libro III de su Vida (Ribadeneyra, 1863: 298) — negó que uno de sus hijos espirituales, el P. Claudio Yayo, fuese nombrado obispo de Trieste por temor a que los hombres se uniesen a su Compañía por afán de vanidad, en lugar de huir de ella.

En su comentario a los capítulos cervantinos XI y XIII, Unamuno aludió a las insistentes correcciones que don Quijote efectuaba sobre las palabras del cabrero respecto al mal de amores que ocasionó la muerte del estudiante Grisóstomo. A partir de esas intervenciones, Unamuno trató de ilustrar la temática amorosa ejemplificando con personajes bíblicos e incorporando la negativa de Íñigo de Loyola a llevar mujeres en su Compañía. Según explicaba Ribadeneyra en el capítulo XIII del Libro III, el santo vasco, juzgando "que no convenía a la Compañía tener cargo de mujeres, por ser cosa embarazosa y muy ajena de nuestro instituto" (VQS, p. 211), logró que el papa Pablo III impidiese que se formase la comunidad femenina bajo la obediencia de los jesuitas dado el "grande estorbo que sería este cargo" (VQS, p. 211). Ante tan esclarecedoras afirmaciones, nuestro polémico pensador exclamaría: " $i Y$ cómo embaraza la mujer!" (VQS, p. 223). No obstante, trató de defender la postura ignaciana rechazando razones de odio o desprecio hacia ésta, pues el fundador de la Compañía de Jesús "la honró en lo que es tenido por más bajo y más vil de ella" (VQS, p. 223).Se basaba Unamuno en el episodio del capítulo IX del Libro III de su Vida, en que Ribadeneyra narraba cómo el mismo Íñigo de Loyola atravesaba la ciudad de Roma acompañado de prostitutas arrepentidas a fin de reubicarlas en el monasterio de Santa María o en alguna casa honrada (Ribadeneyra, 1863: 270-271). Así, además, volvería el catedrático salmantino a compararlo con el hidalgo manchego en lo que respecta al inocente trato con que ambos se dirigieron a las mujeres de dudosa reputación, pues don Quijote se hizo armar caballero (Cervantes, 2008, I: 133) “ciñéndole la espada y calzándole espuela dos mozas de partido" (VQS, p. 223). 
También estos caballeros andantes fueron atacados por seres fantásticos e incorpóreos, y es que, según el capítulo IX de Libro V de su Vida, el demonio se manifestó ante Íñigo de Loyola con la pérfida intención de estrangularlo (Ribadeneyra, 1863: 598). Del mismo modo, don Quijote había de enfrentarse constantemente a encantadores que cambiaban y desordenaban la realidad. Es más, en el capítulo XVII de la obra de Cervantes, el Caballero de la Triste Figura creyó ser golpeado por un brazo gigante y mágico aunque, con la lectura del capítulo anterior, puede apreciarse que se trataba, por una parte, del ataque del arriero celoso ante las palabras románticas que este dedicaba a su amante, Maritornes; $y$, por otra, el del ventero al entrar en la confusa oscuridad. Por tanto, pese a que el hidalgo sí que afirmaba el origen fantástico de tal violencia (Cervantes, 2008, I: 242-250), no hay duda alguna de que la procedencia de los golpes recibidos por don Quijote no fue fruto de ningún efecto sobrenatural por más que Unamuno insistiese en vincularlo con san Ignacio.

Llegados al capítulo XXVI, aparece la analogía en cuanto a la práctica de la reclusión para penitencias. Íñigo de Loyola, según el capítulo VI del Libro I de su Vida, dejó de comer y de beber en el Monasterio de Santo Domingo (Ribadeneyra, 1863: 51); y don Quijote de la Mancha también hizo un retiro basado "en no comer y en hacer otras asperezas equivalentes"(Cervantes, 2008, I: 359), según su intérprete bilbaíno, para curarse de las burlas y desahogar su amor por la sin par Dulcinea del Toboso (VQS, p. 267).

En el capítulo XXIX del Quijote tuvo lugar la conversión de Dorotea en la princesa Micomicona, quien se presentó junto al barbero por escudero ante el Caballero de la Triste Figura para pedirle que la ayudase a salvar su reino. Entonces el héroe caballeresco mostró la fuerza de su fe garantizando ante la fingida princesa la reconquista de sus dominios (Cervantes, 2008, I: 410). Tal afirmación supuso para Unamuno una incuestionable prueba de la confianza de don Quijote en Dios y en sí mismo, ya que, al igual que hizo Íñigo de Loyola, si creía en Dios y actuaba en su nombre, sin duda saldría victorioso. De ese modo se mostraría años antes san Ignacio al enunciar su confianza en la voluntad divina, tal y como ejemplificaba Miguel de Unamuno en referencia al momento en que el religioso se dirigió al padre Laínez, desesperado por el destino de la fundación de un colegio en Padua, asegurándole con total certeza que todo iba a salir bien - capítulo VI de Libro III de su Vida (Ribadeneyra, 1863: 260)—.

Estos defensores de la caballería, divina y andante, tuvieron fe en Dios y en sí mismos, actitud que Iglesias describió como propia de la tesis quijotista basada en pensar que el héroe está donde está únicamente por su excelencia, lo cual lo hace sentir incomprendido y, por consiguiente, hallarse en la única compañía de Dios hasta el punto de verlo en sí mismo y ramificándose así una fe de dos direcciones: "fe en Dios mismo, y, por consecuencia, fe en sí mismo, depositario de designios divinos" (Iglesias Ortega, 1990: 868). Ya lo proclamaba el mismo don Quijote ante la princesa Micomicona: "con la ayuda de Dios y la de mi brazo, vos os veréis presto restituida en vuestro reino y sentada en la silla de vuestro antiguo y grande estado" (Cervantes, 2008, I: 410).

La última comparación con la Primera Parte del Quijote se establece en referencia a su capítulo XXXV, donde tiene lugar la famosa batalla de los cueros de vino en que el hidalgo manchego soñó combatir gigantes y, a consecuencia de ello, acuchilló las reservas del ventero durante la onírica lucha (Cervantes, 2008, I: 488). El rector de Salamanca hizo alusión a ese enfrentamiento en sueños de don Quijote contra cria- 
turas malignas para compararlo con Íñigo de Loyola en un momento — citado en el capítulo IX del Libro V de su Vida - en que este creyó ver demonios o fantasmas y decidió dirigirles la palabra para avisarles de que, si lo buscaban por algún mandato divino, lo asumiría; mientras que de no ser así, no tenía motivo alguno para temerlos, evidenciando nuevamente su plena confianza en Dios (Ribadeneyra, 1863: 597-598).

Además, Unamuno finalizó el comentario a este capítulo XXXV de la novela cervantina refiriéndose a sus semejanzas en cuanto a la carencia de higiene en un intento por resarcir al ilustre loco de la Mancha del denigrante apunte de Cervantes sobre sus piernas "no nada limpias" (Cervantes, 2008, I: 488), aludiendo así que tanto este como san Ignacio pertenecían a momentos históricos en los que no se atendía tanto al cuidado y a la limpieza (VQS, p. 291).

Con estas referencias terminaba la comentada analogía entre el santo y las aventuras de don Quijote de la Mancha en la Primera Parte de su novela para proseguir con la interpretación unamuniana de algunos de los episodios hallados en la Segunda Parte. Así, al final de sus referencias al capítulo XVII de ésta, en que don Quijote se convierte en el Caballero de los Leones (Cervantes, 2008, II: 169), Unamuno estimó que esa osadía del hidalgo constituía una muestra más de su fe, ya que él sabía que Dios le enviaba ese león, y "con solo verlos entendió la voluntad del Señor y obedeció según la tercera y más perfecta manera de obedecer que hay" (VQS, p. 370), que sería, según tomó de palabras del mismo Ignacio de Loyola, la siguiente afirmación: "cuando hago esto o aquello sintiendo alguna señal del Superior, aunque no me lo mande ni lo ordene" (Ribadeneyra, 1863: 558). Según el profeta del Caballero de la Fe, "Dios quiso, sin duda, probar la fe y obediencia de don Quijote como había probado las de Abraham mandándole subir al monte a sacrificar a su hijo" (VQS, p. 370). Al enfrentarse al león, don Quijote actuó, por tanto, con la misma seguridad en Dios que su antecesor vasco.

En lo referente a las visiones del hidalgo manchego durante su estancia en la cueva de Montesinos, Unamuno innovó en su habitual quehacer literario y, en lugar de interpretar directamente la mística experiencia, animó a los lectores a retomar el capítulo XXIII de la Segunda Parte del texto de Cervantes; aunque, para apoyar la veracidad de su caballero, no dejó escapar la oportunidad de mencionar que otros siervos de Dios anteriores a él también sucumbieron a momentos de éxtasis que los hicieron ver imágenes similares a las que confesó don Quijote. Así, aunque no se refiriese directamente a Ignacio de Loyola, probablemente pensaba en él -entre otros - para tales afirmaciones, pues también el santo, según narró Ribadeneyra en el capítulo XI del Libro II de su Vida, "claramente vio cómo Dios Padre, volviéndose a su unigénito Hijo, que traía la cruz a cuestas, con grandísimo y entrañable amor le encomendaba a Ignacio y a sus compañeros" (Ribadeneyra, 1863: 167). Y, en el capítulo consecutivo, el fundador de la Compañía de Jesús también vería ascender a los cielos el ánima de uno de sus hermanos de fe.

De hecho, con el siguiente capítulo de la Segunda Parte del Quijote, Unamuno sería más explícito que en el anterior, llegando a hacer la recomendación de leer al "piadoso Padre historiador de Íñigo de Loyola para convencernos de la verdad de las visiones de éste" (VQS, p. 376). Tomó a Ribadeneyra como autoridad historiográfica aceptada para dar mayor realismo a tales experiencias místicas; mientras que al otro autor tachado de historiador, Cervantes, lo acusaba de no haber leído la obra de san Ignacio o, de hacerlo, de no recordarla bien — pues la ubicó veinte años antes de la publicación de la Primera parte del Quijote - al no considerar esta comparación, tan 
recurrente para Unamuno, en la cual se contaban "las visiones del caballero andante de Cristo" (VQS, p. 375) y, en su lugar, suponer que fueron inventos y fantasía del hidalgo. Asumiendo así nuestro autor que hubo de ser don Quijote, y no Cervantes, quien sí leyó con detenimiento la Vida de San Ignacio de Loyola - a pesar de que en la obra cervantina no haya mención alguna de esto- y comprendió que, como el mismo santo dijo, las personas que no entendían de visiones eran aquellas que nada sabían sobre el espíritu humano (VQS, p. 375).

Si en el comentario al capítulo XXIII el pensador vasco recomendó confiar en la palabra de don Quijote, el análisis del XXIV se convirtió en una excusa para convencer a los lectores de la veracidad de las visiones de su Caballero de la Fe, tomando como referencia de autenticidad asan Ignacio de Loyola y, a su vez, defendiendo la teoría de que, fuesen sueños o realidad, si él así lo vio y lo tomó por cierto, no había motivos para censurarlo o menospreciarlo bajo la excusa de que era algo mental en lugar de tangible: "Si la vida es sueño, ¿por qué hemos de obstinarnos en negar que los sueños sean vida? Y todo cuanto es vida es verdad. Lo que llamamos realidad, ¿es algo más que una ilusión que nos lleva a obrar y produce obras?” (VQS, p. 377).

Sobre este aspecto Luis Iglesias ofreció otro punto de similitud basado en asumir que ambos entendieron la vida como un sueño (Iglesias Ortega, 1990: 865). No obstante, esta afirmación resulta dudosa, pues, si bien es cierto que ambos tuvieron ensoñaciones - especialmente don Quijote- que consideraron verídicas, en ningún momento confirmaron entender así sus vidas. Por tanto, convendría matizar a este respecto que la comparación no coincide con la línea de las anteriores a partir de parecidos obtenidos a través de episodios y citas concretas de ambas obras, sino que se trata de una interpretación con la que se podría presentar cierta discrepancia; y es que la hipótesis de la vida como un sueño no procede de la novela cervantina sino del ensayo unamuniano. El tópico literario de entender la vida como un sueño del que despertaremos cuando muramos lo trasladó el rector salmantino a la visión de la locura quijotesca, siendo la vida, a la vez, sueño y locura, y únicamente cuando estamos a punto de despertar es cuando perdemos esa visión idealista del mundo y caemos en la cordura de Alonso Quijano. Una cordura que recobró en su lecho de muerte y que también se tornó purificadora. La teoría que el pensador vasco defendería consistió en aceptar que los sueños forman parte de la vida y que, por ello, pueden ser reales porque nos ayudan a vivir. Así, las ensoñaciones de don Quijote - por ejemplo en la cueva de Montesinos - o las visiones de san Ignacio sobre Dios, serían sueños y serían realidades a su vez, pues influyeron en sus conductas; pero en ningún momento estos personajes tuvieron conciencia de que la vida tenía que vivirse a modo de sueño, ni así lo expresaron ni ellos ni mucho menos sus "biógrafos". Para Ribadeneyra, las visiones ignacianas tuvieron realidad casi física, no onírica; y Cervantes dejó entrever en algunos episodios - como el de los cueros de vino o la mencionada cueva de Montesinos - que don Quijote soñaba en sentido completamente literal, por haberse dormido, no por tener conciencia de que tenía alucinaciones a las que podría dar la misma valía que a la realidad. Esas ideas son completa y exclusivamente unamunianas, y las usó nuestro autor para referirse a su Caballero de la Fe, no como apoyo de analogías con Íñigo de Loyola.

En efecto, puede hallarse cierta coincidencia sobre esta idea en el hecho de que también Ribadeneyra, aunque no entendiese las experiencias místicas de su padre espiritual como meros sueños, explicase al inicio de la Vida de San Ignacio de Loyola que la realidad es un sueño que, con el despertar, conduce a la espiritualidad: 
"vestida su ánima y alumbrada de nueva luz del cielo, como quien despierta de un profundo sueño, abrió los ojos para ver lo que antes no veía" (Ribadeneyra, 1863: 52). Sin embargo, tampoco esta hipótesis casaría con la teoría de Iglesias Ortega porque san Ignacio actuaba de manera espiritual, es decir, ya había despertado del sueño de la vida terrenal.

Continuando con el capítulo XXV del segundo Quijote, Unamuno lo usó para abarcar el aspecto de la humildad que el hidalgo manchego parecía mostrar en la venta con el hombre que había hallado en el camino llevando lanzas y alabardas sobre su jumento, pues lo ayudó don Quijote "ahechándole la cebada y limpiando el pesebre, humildad que obligó al hombre a contarle lo que le pedía" (Cervantes, 2008, II: 239) pese a no ser, a juicio de nuestro autor, "lo mentado que merece serlo. Y ésta es, sin duda, una de las grandes aventuras de nuestro Caballero" (VQS, p. 378). Además "lo hizo más sencillamente aún que Íñigo de Loyola" (VQS, p. 379), a quien supera en esta ocasión, ya que en el ejemplo tomado del capítulo II del Libro III de su Vida, san Ignacio trabajó como cocinero con la intención de adoctrinar a los demás provocándoles "con su ejemplo al deseo de la verdadera humildad" (Ribadeneyra, 1863: 245) mientras que don Quijote sencillamente lo hizo porque salió de sí.

El capítulo XXIX en que el Caballero de la Triste Figura halló una barca y creyó con ella atravesar la línea equinoccial en cuestión de minutos, cuando realmente ni siquiera se había alejado de la orilla, se vincula para Unamuno con el capítulo IV del Libro V sobre el santo vasco cuando este asumió que también acataría gustoso cualquier misión encomendada por el dictamen del Papa, y "lo haría y obedecería no solo con paz, mas aun con contentamiento y alegría de su ánima" (Ribadeneyra, 1863: 561).

En el capítulo XXXII, la primera comparación entre ambas figuras se presenta mediante la transferencia de la denominación religiosa, pues, si bien Ignacio de Loyola fue santificado, Unamuno se dirigió a su protagonista exclamando: “¡Oh, don Quijote, mi san Quijote! Sí, los cuerdos canonizamos tus locuras” (VQS, p. 397). Los dos personajes habrían sido nombrados santos del cristianismo español. También nuestro autor escribió sobre los ataques del eclesiástico en la mesa de los Duques contra la vehemencia quijotesca(Cervantes, 2008, II: 295) y advirtiendo que también el fundador de la Compañía jesuita fue, según el capítulo XV del Libro I de su Vida, sermoneado por el vicario del convento de dominicos de san Esteban, de Salamanca, por carecer de estudios concretos de Teología(Ribadeneyra, 1863: 105).

Una nueva analogía se halla con el capítulo XLIV del segundo, respecto a la rotura de medias del antaño Alonso el Bueno y la consecuente cavilación unamuniana sobre la miseria. Una reflexión, sin duda, muy al caso para recordar a Íñigo de Loyola y su voto de austeridad, pues también "el pobre don Quijote hizo algo así como voto de pobreza al principio de su carrera y salió de su casa sin blanca y se negaba a pagar, creyéndose libre de ello por fuero de caballería" (VQS, p. 415). Es interesante cómo adaptaba para sí el paralelismo divinizando ante el hecho de que don Quijote no pagase los servicios que consumía y acusando, además, de que fueron las insistencias del ventero que lo había armado caballero las que terminaron provocando que rompiese ese voto $\mathrm{y}$, como consecuencia, fuese perseguido por todo tipo de penurias.

Lo curioso a este respecto es que san Ignacio se "comenzó a agujerear las suelas de los zapatos, yéndolas poco a poco rasgando" (Ribadeneyra, 1863: 95) debido a los esfuerzos del mismo por huir de toda suntuosidad. Sin embargo, cuando don Quijo- 
te tuvo que zurcirse las medias con un hilo de color diferente al original, se apenó visiblemente de la pobreza que aparentaba (Cervantes, 2008, II: 391). Según Unamuno, aun teniendo esto en cuenta, todavía el Caballero de los Leones continuaba actuando igual que san Ignacio, ya que su actitud inicial fue la de predicar la pobreza y sus tristezas posteriores ante las carencias económicas que hubo de padecer fueron fruto de su angustia vital, pues, según nuestro autor, "la pobreza no es la escasez de recursos pecuniarios para la vida, sino el estado de ánimo que tal escasez engendra" (VQS, p. 415).

Respecto al capítulo XLVI, a colación de la composición y cante del romance de nuestro hidalgo, el rector de Salamanca sustituyó la comparación por la oposición al santo vasco, en esta ocasión, para engrandecer a don Quijote y sus aficiones poéticas sobre san Ignacio y su rechazo a tener coros en su Compañía asumiendo que "no es de esencia de la religión el tener coro" (Ribadeneyra, 1863: 348). Para Unamuno, el canto era una forma de expresión del alma. Igualmente, a fin de no desprestigiar en exceso a Íñigo de Loyola, figura que tan repetidamente había ligado a su hidalgo, aprovechó sus comentarios acusativos para culpabilizar nuevamente a aquellos que lo acompañaban, refugiándose en que también en la Vida del santo podían hallarse referencias a sus inclinaciones musicales y que fueron los demás jesuitas quienes incentivaron la prohibición del coro (VQS, pp. 420-421). No obstante, esto no fue más que otra de las manipulaciones unamunianas, apropiándose subjetivamente de los fragmentos del texto de Ribadeneyra que más le convenían para fomentar la polémica y asumir que aquello se debía a las imperfecciones que acompañaban al santo, a los errores de su entorno, en lugar de recordar que la negativa al coro fue decisión directa del propio san Ignacio, y que el autor de su biografía insistió en comentar positivamente las virtudes y ventajas que la música despertaba en las personas, llegando a preguntarse: “¿No serán tan agradables a Dios nuestro Señor los buenos corazones como las buenas voces, y las alabanzas de santas costumbres como las de dulces músicas?" (Ribadeneyra, 1863: 416).

Otra similitud entre estos dos caballeros es que ambos anhelaron alcanzar la gloria y la fama, actuando en consecuencia, y es que también Ignacio de Loyola, antes de tomar el camino de Dios, ansiaba la honra y el renombre militar, a la vez que en su cambio de rumbo imitó a aquellos santos que precisamente daban ejemplo.

Además, tal y como Santiago Montero establece, tanto san Ignacio como don Quijote se refugiaron en ideales femeninos a quienes rindieron "un culto apasionado, de intachable pureza" (Montero Díaz, 2005: 102): en el caso del primero, sería la Virgen María, y en el del segundo, fue Dulcinea del Toboso.

La última analogía del ensayo unamuniano tendría lugar en referencia al capítulo final de la Segunda Parte del texto cervantino, en que el bueno de Alonso Quijano, postrado en la cama, fenecía ante las lágrimas de sus seres queridos. A su vez, nuestro autor también trajo a sus páginas el fallecimiento del fundador de los jesuitas, cincuenta años anterior a la de don Quijote, en su lecho, sin reunir a muchas personas alrededor, "como se mueren los verdaderos santos y los verdaderos héroes, casi como los animales se mueren: acostándose a morir" (VQS, p. 517). Esto es, que ambos perecieron de forma semejante, acostándose para expirar, a sabiendas de que así sucedería, a pesar de que la despedida de san Ignacio tuvo lugar la noche antes de morir, sin llegar a estar postrado; mientras que el Caballero de la Triste Figura lo hizo desde la cama y acompañado. San Ignacio "murió a los sesenta y cinco años de su vida" (Ribadeneyra, 1863: 509); y don Quijote, que comenzó a los cincuenta su 
primera salida, en 1604, rondaría una edad similar a la del santo jesuita al término de su ajetreada vida.

Tras el fallecimiento del fundador de la Compañía de Jesús, este dejó escritas una serie de enseñanzas, de la misma forma que Unamuno trató de hacer constar con su Cristo Hispánico. Y al igual que el biógrafo de Íñigo de Loyola estimaba como el mayor milagro que se fundase la Compañía de Jesús, Unamuno se preguntaba:

[...] ¿no hemos de tener nosotros por el milagro mayor de don Quijote el que hubiese hecho escribir la historia de su vida a un hombre que, como Cervantes, mostró en sus demás trabajos la endeblez de su ingenio y cuán por debajo estaba, en el orden natural de las cosas, de lo que para contar las hazañas del Ingenioso Hidalgo y tal cual él las contó, se requería? (VQS, p. 525).

Santiago Montero discrepa de Unamuno en lo que respecta a los parecidos extremos entre san Ignacio de Loyola y don Quijote de la Mancha, pues el pensador bilbaíno no solo hallaba concordancia entre sus actos, sino que también descubría semejanzas reflejadas en sus psicologías, a diferencia de Montero Díaz, que en sus conductas y caracteres no ve sino diferencias:

Las superficiales analogías externas sugeridas ya por Voltaire y desarrolladas desde Castelar a Unamuno, apenas justifican otra cosa que un simple juego de ingenio. Las afinidades psicológicas — más profundas - que el propio Unamuno expone con sutil penetración tampoco agotan en su totalidad la significación de ambos héroes (Montero Díaz, 2005: 106).

De cualquier modo, y coincidiendo con Iglesias Ortega, parece estar claro que el "fantasma ignaciano persiguió siempre a nuestro autor, al antiguo discípulo de los jesuitas, devenido, con el tiempo, de fervoroso congregante mariano en 'creyente descreído"' (Iglesias Ortega, 1990: 872). Se pregunta así Iglesias si pudo tratarse de una venganza personal de Unamuno contra los jesuitas y su escaso interés mostrado hacia la obra de Cervantes.

Con independencia del rechazo unamuniano a la Compañía, Íñigo de Loyola fue otro Caballero de la Fe. De ahí extrajo el catedrático salmantino la relación entre la caballería y la santidad. Por eso, aprovechando que venía de la España en la que "la caballería era, a lo humano, lo que la santidad a lo divino" (Iglesias Ortega, 1990: 856), insistió constantemente en buscar analogías entre ambas vidas, pues en el mismo estilo de la Compañía de Jesús residía su aspecto militar, que configuraba a los suyos como unos santos guerreros. Para Unamuno, la moral residía en el combate, la lucha por transcurrir entre los dos mundos: el caduco y el inmortal. Fue su forma de ver paz en la guerra.

Iglesias Ortega establece dos desemejanzas fundamentales entre ambos caballeros. Por un lado, la oposición entre la colaboración de don Quijote en quehaceres cotidianos sin segundos fines, frente a la participación de san Ignacio en oficios caseros con la directa e interesada intención de dar ejemplo de verdadera humildad; pues, para el rector de Salamanca, intentar dar apariencia de persona humilde reflejaba, en realidad, soberbia. Nuestro autor rechazaba todo estatismo consecuente del miedo a ser criticado y, por tanto, ensalzó al hidalgo manchego frente al santo vasco por lanzarse, el primero, a la aventura sin importarle en absoluto el ser tomado por loco. 
La otra diferencia es la de la música: Íñigo de Loyola, hallando a Dios en el canto y gustándole tanto, prohibió el coro en su Compañía (Iglesias Ortega, 1990: 870-871). Aunque, siendo estrictos, si la comparación fue entre don Quijote y el santo, y ambos se confesaron amigos de las melodías -independientemente de su nula aplicación jesuita a posteriori-, más que desemejanza, sería una coincidencia, pues tampoco el Caballero de los Leones instauró el canto en su orden caballeresca, sino que lo consideró cuando ya había cesado de ser don Quijote y comenzaba a convertirse en el pastor Quijotiz.

Sin embargo, ni Luis Iglesias - ni mucho menos Miguel de Unamuno- mencionaron otras diferencias que, respecto al criterio unamuniano, resultan incluso más llamativas. Y es que, en primer lugar, san Ignacio deseaba "que le mudase el nombre" (Ribadeneyra, 1863: 25); mientras don Quijote exclamaba bíblicamente "yo sé quién soy" (Cervantes, 2008, I: 146) o, como abarcó Unamuno, "al decir "iyo sé quién soy!', no dijo sino 'iyo sé quién quiero ser!'” (VQS, p. 190). Bien es cierto que, inicialmente, el ingenioso hidalgo también cambió su nombre de Alonso Quijano a don Quijote de la Mancha; no obstante, considerando la comparativa entre el ya asumido caballero manchego y san Ignacio, el primero sí que efectuó una férrea defensa de su conciencia de identidad.

En segundo lugar, la definición que el fundador de la Compañía de Jesús aportó sobre la verdad se basaba en que "bien puede ser que sea apretada y combatida, pero nunca jamás oprimida ni ahogada" (Ribadeneyra, 1863: 481); mientras que, para Miguel de Unamuno, la verdad admitía numerosas interpretaciones en función de la vehemencia con la que cada uno creyese en la suya propia y la intención con que actuase a partir de ella.

Y, por último, el aspecto de la gloria. Aunque algo sobre esto comentó Unamuno, pasó de puntillas sobre el hecho de que el fundador de la Compañía de Jesús, anteriormente "muy atormentado de la tentación de la vanagloria" (Ribadeneyra, 1863: 74), la entendía como algo negativo y pecaminoso, en oposición a un don Quijote que la ansiaba y buscaba con ahínco.

Igualmente, teniendo en cuenta la comparación de la obra cervantina y el texto de Ribadeneyra, hay más de un aspecto secundario en que estos personajes difirieron y, sin embargo, nuestro autor también lo omitió. Uno de ellos es la partida. El fundador de la Compañía de Jesús partió acompañado de dos criados a los que solicitó que se marchasen cuando ya había avanzado su camino. De hecho, "aunque muchos se le ofreciesen de hacerle compañía" (Ribadeneyra, 1863: 71), "nunca lo quiso hacer, por gozar más libremente de su soledad" (71). Por el contrario, don Quijote abandonó el caminar en solitario durante su primera salida y fue acompañado de su escudero Sancho Panza, quien estuvo junto a él en la mayor parte de sus aventuras.

También es destacable la distinta perspectiva en el enfoque hacia a los musulmanes, pese a la escasa diferencia temporal entre ambas obras. En la Vida, estos constituían el enemigo; mientras que en el Quijote, su propio autor original, según el juego cervantino aceptado como real por Unamuno, era árabe: Cide Hamete Benengeli. Es decir, tanto para el Miguel del siglo XVII como para el del siglo XX, los musulmanes tuvieron valía literaria.

Por último, en el capítulo XXXI de la Segunda Parte del Quijote tuvo lugar la terrible afrenta, según nuestro autor, en que el eclesiástico se dirigió al nuevo Cristo Hispánico como "don Tonto" (Cervantes, 2008, II: 295). La similitud entre don Quijote y san Ignacio sí que se vería reflejada en el ensayo unamuniano respecto a los 
ataques del vicario cuando se refirió a este y a sus seguidores como "unos simples idiotas y hombres sin letras" (Ribadeneyra, 1863: 105) por hablar de las virtudes y los vicios ser teólogos. No obstante, un adjetivo similar al que Unamuno censuraba en el cura cuando calificaba a su Caballero de la Fe también fue empleado por el biógrafo de su santo, el padre Ribadeneyra, cuando describía a un hombre italiano de Basán llamado Antonio como un "hombre anciano, lego e idiota y muy sencillo, mas severo y grave, y de los hombres tenido por santo" (Ribadeneyra, 1863: 161).

Una respuesta plausible ante tantos aspectos ignorados por Unamuno en su comparación de ambas figuras sería la evidencia de la enorme apropiación del texto cervantino que este efectuó a fin de tomar aquello que le servía y manipular o, sencillamente, obviar, todo comentario que pudiera oponerse a la defensa de sus ideas. Si el pretexto de la comparación era ensalzar a don Quijote, ubicándolo a la altura - e incluso superando dicha altura - del fundador de la Compañía de los jesuitas, y reforzar su entidad como nuevo Cristo Hispánico fundador del cristianismo quijotesco, no ha de sorprender entonces que evitase cualquier referencia que lo alejase de tal propósito. Y esto son en realidad el Quijote y don Quijote para Unamuno: un pretexto. Como mucho, un pre-texto.

En lo que respecta al biógrafo del santo, Aguilera se refirió a este como "un escritor sobre temas religiosos, sentidos muy a la española" (Aguilera, 1961: vii). Aquel que Unamuno mencionaría en una carta a Clarín (31 de mayo de 1895) como "mi maestro el Sr. Menéndez Pelayo" (Alas, 1941: 52), ya subrayó que Ribadeneyra fue un literato magnífico, lo cual, considerando la autoridad que a su criterio concedía Miguel de Unamuno ${ }^{3}$, podría justificar el respeto de este hacia el autor jesuita. El hecho de que Menéndez Pelayo se hiciese eco de las palabras con las que Tamayo Vargas categorizó a Cervantes en el siglo $\mathrm{XVII}^{4}$ y escribiese que este "era poeta, y solo poeta, ingenio lego, como en su tiempo se decía” (Menéndez Pelayo, 1994: 744), probablemente incentivaron los ataques del rector de Salamanca hacia el mismo, estimándolo un autor inferior a su obra (a pesar de que las afirmaciones de su maestro carecían de toda malicia). Por tanto, si el mismo Menéndez Pelayo reconoció la Vida de San Ignacio como una de las mejores biografías dentro del humanismo de la modernidad en fondo y en forma (Aguilera, 1961: viii), también resulta esperable que Unamuno apreciase esta Vida como una escritura digna de estima.

Conforme la biografía se inicia, el padre Ribadeneyra se dirige a todos los hermanos de la Compañía de Jesús, al igual que después haría Unamuno con don Quijote, tomando a san Ignacio como guía y ejemplo a imitar:

[...] nosotros, habiendo recibido de la mano de Dios, nuestro Señor, a nuestro padre Ignacio por guía y maestro, y por caudillo y capitán de esta milicia sagrada, debemos tomarle por espejo de nuestra vida y procurar con todas nuestras de seguirle, de suerte que si por nuestra imperfección no pudiéremos sacar tan al vivo y tan al propio el retrato de sus muchas y excelentes virtudes, a lo menos imitemos la sombra y rastro de ellas (Ribadeneyra, 1863: 11).

3 "La postura de Unamuno frente a Menéndez Pelayo tiene muchos matices, pero predomina el respeto y la admiración” (Morón Arroyo, 1997: 12). El propio Unamuno (1959: 168), recordó nostálgico los años en que asistió a sus clases: "seguí dos cursos completos y saqué valiosos apuntes".

$4 \quad$ Menéndez Pelayo "se refirió, de prisa, a Cervantes, en la Historia de las ideas estéticas, y se le escapó a él mismo, lo de ingenio lego, probablemente aludiendo — como cosa sabida - al acuñador de la frase: Tamayo de Vargas" (Porqueras Mayo, 2003: 32). 
También Ribadeneyra, como encargado de predicar la obra del santo, guardaría relación con lo que siglos después haría el proclamado profeta del nuevo Cristo Hispánico. Unamuno actuaba en sus escritos de forma semejante a como lo hizo el padre Ribadeneyra. Es más, al igual que san Ignacio contó con varios biógrafos, también el Quijote dispuso un juego de narradores en que Cervantes dictó la vida del hidalgo manchego esencialmente a través de Cide Hamete Benengeli, siendo Unamuno aquel que, años después, sabría cómo interpretarlo para transmitir la creación de su Caballero de la Fe.

Rogelio García ya evidencia las semejanzas entre Ribadeneyra y Unamuno incluso en los títulos de sus dos obras: Vida de Don Quijote y Sancho y Vida del bienaventurado Padre Ignacio. Es inevitable coincidir con García cuando advierte que "el estilo literario del libro de Unamuno es el hagiográfico, la exaltación panegírica de las virtudes y milagros del santo, aplicada a don Quijote (García Mateo, 1999: 131).

En la misma dedicatoria de la Vida de San Ignacio "Al cristiano lector", Ribadeneyra confesó lo siguiente: "Algunas cosas he añadido en este libro de romance, y declarado que no estén en el primero, o no tan explicadas como para el romance era menester" (Ribadeneyra, 1863: 5). Es decir, este biógrafo hizo lo mismo que haría Unamuno cuando revisó su inicial borrador del ensayo en dos ocasiones, añadiendo comentarios, reescribiendo e interpretando (Navarro, 1992: 120-123). De hecho, la primera reescritura que Unamuno realizó antes de publicar su ensayo y que prácticamente duplicó la extensión del autógrafo inicial fue aquella en la que incorporó la amplia comparación entre don Quijote y san Ignacio.

Es más, el biógrafo del santo de Azpeitia, al igual que Miguel de Unamuno con su Caballero de la Fe, equiparó la acción de su protagonista a la de Jesucristo, el arquetipo que debe ser imitado, y otros santos al explicar que, tras reposar su lesión, "iba cobrando fuerzas y aliento para pelear y luchar de veras, y para imitar al buen Jesús, nuestro capitán y Señor, y a los otros santos, que por haberle imitado merecen ser imitados de nosotros" (Ribadeneyra, 1863: 27). Para el catedrático salmantino, la coincidencia entre don Quijote y otras figuras ligadas a la santidad nacía del esfuerzo por seguir el ejemplo de Jesucristo:

He aquí el sentido más profundo de las comparaciones que establece Unamuno entre don Quijote, san Ignacio, pero también santa Teresa y otros santos, a saber: no quedarse en ellos mismos sino llegar hasta el modelo común de todos ellos, esto es, que el "loco" manchego a veces es una expresión del mismo Cristo, de la locura de su cruz (García Mateo, 1999: 136).

Por tanto, también hemos de suponer que, si bien Unamuno insistía en que la Vida del religioso vasco hubo de encontrarse en la biblioteca de Alonso Quijano que, en su conversión al caballero don Quijote, contó para inspirarse con el ejemplo de lo que entre sus páginas leyó, es igual de asumible que el profeta de este Cristo Hispánico siguiese su ejemplo, tal y como sugirió hacer al resto de españoles a lo largo de todo el ensayo, y leyese la mencionada biografía para imitar la acción narrada por Ribadeneyra, encargado de proclamar al mundo las hazañas religiosas de su caballero a lo divino, el santo Íñigo de Loyola. Si don Quijote es paralelo a san Ignacio, también los autores de ambas vidas mostraron cierta analogía.

Pero no solo con Pedro Ribadeneyra se hallará similitud. Del mismo modo que hubo ocasiones en las que Unamuno se igualó a don Quijote de la Mancha en algunas 
de sus actuaciones y pensamientos, tampoco sería desacertado suponer al escritor vasco desempeñando la función de alter ego de Ignacio de Loyola, pues si bien el jesuita mostraba semejanzas con don Quijote, y este tenía parecido con el rector de Salamanca, podría deducirse entonces que san Ignacio y Unamuno también guardaron relación. Es más, la analogía entre don Quijote y san Ignacio sería aplicable a Unamuno, simplemente teniendo en cuenta la siguiente descripción que de este dispone Ribadeneyra: "Su vida, ni es solamente activa, como las militares, ni puramente contemplativa como las monacales, sino mixta, que abraza juntamente la acción de las obras espirituales, en que se ejercita, y la contemplación, de donde sale la buena y fructuosa acción" (Ribadeneyra, 1863: 344). Así sucedía con Unamuno, que era contemplativo y, a la vez, admiraba y demandaba la acción.

De esta forma debió de asumirlo él, al igual que también lo pensó Antonio Machado que, en 1905, diría sobre Unamuno: "Sirve honradamente a su Dulcinea este caballero siempre dispuesto a todo noble combate. Admírole yo por su temple de espíritu y téngole comparado con Íñigo de Loyola, su conterráneo" (Machado, 1990: 91-92). Y es que, en ese mismo año, Machado destinaría, además, unos versos al autor bilbaíno encabezados con la siguiente dedicatoria: "Por su Vida de Don Quijote y Sancho". Estas estrofas se hallan en la sección "Elogios" de Campos de Castilla (Poesías completas, CLI) e insisten al final en la relación entre Unamuno y el santo:

Tiene el aliento de una estirpe fuerte que soñó más allá de sus hogares, y que el oro buscó tras de los mares.

Él señala la gloria tras la muerte.

Quiere ser fundador, y dice:

Creo; Dios y adelante el ánima española...

$\mathrm{Y}$ es tan bueno y mejor que fue Loyola:

sabe a Jesús y escupe al fariseo (Machado, 1969: 159-160).

Años antes, en marzo de 1895, Unamuno había señalado en su ensayo En torno al casticismo que la forma de catolizar el mundo partiría de castellanizarlo, y destacó al fundador de la Compañía de Jesús como aquel que, procediendo de las mismas tierras que nuestro autor, desempeñó tan ardua tarea y se encargó de ahondar en el espíritu religioso de su patria: "Y de los demás pueblos españoles brotaron espíritus hondamente castellanos, castizamente castellanos, de entre los cuales citaré como ejemplo a Íñigo de Loyola, un vasco. En su obra alienta todavía por el mundo el espíritu de la vieja Castilla" (Unamuno, 2007: 99).

Y Unamuno ensalzó a Íñigo de Loyola en su soneto LVII del Rosario de sonetos líricos, "Piedad castiza", estimando "que no hay más Dios que Dios, y su profeta / Íñigo es, el vasco morabito" (Unamuno, 1999: 368). San Ignacio sería el profeta de Dios mientras que nuestro pensador obraría como profeta del nuevo Cristo Hispánico.

Por otra parte, en lo que a sus vidas atañe, tampoco faltan algunas semejanzas que se reflejarían en el Unamuno quijotesco. Un Unamuno que ya reflejó muchísimas de sus inquietudes y preocupaciones en su Diario Íntimo. También san Ignacio tuvo, entre sus escritos, un Diario espiritual que se encontraba "celosamente guardado [...] en el archivo de Roma" (Iparraguirre y Dalmases, 1982: 6) hasta que el aún estudiante de la Universidad de Padua, Pedro de Ribadeneyra - que publicaría su Vida en 1546(Iparraguirre y Dalmases, 1982: 3)—, tuvo acceso a él. 
Otro aspecto relevante es que, al igual que Unamuno padecía de constantes crisis de fe y dudas sobre la existencia de Dios —el mismo ensayo Vida de Don Quijote y Sancho es otra evidencia más de ese esfuerzo desmedido por querer creer y por defender la fe sanchopancesca: la fe que duda-, san Ignacio también sufría de ánimos y confianza en su fe: “¿Pues cómo, Señor, me queréis echar de vos? ¿Por qué permitís que ande tan triste, y así me aflija mi enemigo, que me da grita, preguntándome cada hora: ¿Dónde se te ha ido tu Dios?”(Ribadeneyra, 1863: 51). Sin embargo, Ribadeneyra especificaría más adelante que el fundador de los jesuitas jamás dudaría de la existencia de Dios, como sí le sucedió de continuo a Unamuno; no obstante, sí es cierto que ambos padecieron congoja y desesperación al sentir el abandono de Dios en determinados momentos de sus vidas.

Íñigo de Loyola se mostró en todo momento disconforme con muchas de las leyes eclesiásticas, llegando a proponer "la reformación de la Iglesia" (Ribadeneyra, 1863: 400), algo muy lícito para un catedrático salmantino de pronunciado anticlericalismo que, quizá motivado por ello, mostró tan evidenciado rechazo hacia la Compañía de Jesús. En cualquier caso, el religioso jesuita decidió alzarse durante un periodo de cambio hacia una mayor exaltación católica basada en la defensa de que la vida se había de concebir de manera distinta, pues había una nueva actitud espiritual que afectaba a todas las manifestaciones de la actividad humana, lo mismo "literarias, ascéticas, sociales, que políticas, elevándolas a una altura trascendente y católica desconocida hasta entonces" (Iparraguirre y Dalmases, 1982: 9). Fue inevitable que eso no repercutiese sobre su vida, convirtiéndolo en un abanderado de ese movimiento y, del mismo modo, también Unamuno halló refugio en don Quijote para encontrar al representante que liderase la oposición ante el pensamiento dominante, una oposición que también él ansiaba conseguir con el ejemplo del Caballero de la Triste Figura. Así, a la par que san Ignacio sería el fundador de una nueva religión que no se había visto con anterioridad, el rector de Salamanca trató de instaurar, a partir de los actos y palabras de su Caballero de la Fe, el renombrado cristianismo quijotesco.

Asimismo, no solo en determinadas actitudes es posible encontrar algo del religioso jesuita en Unamuno. Si, según éste, don Quijote había leído las hazañas que Ribadeneyra escribió a fin de tratar de acatarlas en servicio de Dios y para mejora del mundo, también nuestro autor, al reescribir su particular Quijote, se pudo haber esforzado por actuar de forma semejante a la que predicaría su paisano Íñigo de Loyola a través de los cuatro avisos dictados para la Compañía de Jesús, ya que se hallan algunas semejanzas entre lo que san Ignacio predicó y lo que después Unamuno redactó sobre su protagonista manchego.

El primero de los avisos ignacianos fue el de "hallar a Dios nuestro Señor en todas las cosas" (Ribadeneyra, 1863: 355), lo cual, sin duda alguna, acató a la perfección nuestro autor, pues en más de la mitad de las referencias a aventuras y conductas quijotescas es posible encontrar reseñas bíblicas por parte de Unamuno, cuando no paralelismos directos del hidalgo manchego con apóstoles, Jesucristo o con Dios.

El segundo aviso dictaminaba que "todo lo que hicieren lo enderecen a la mayor gloria de Dios" (Ribadeneyra, 1863: 355). En este caso, el pensador bilbaíno defendió el hecho de que la mayoría de las decisiones tomadas por su ilustre loco estuviesen determinadas por su confianza en Dios y los designios para él previstos; además, aunque también Unamuno abogase por que don Quijote buscase su propia gloria, teniendo en consideración las asiduas referencias en las que se establecieron paralelismos entre el mismo caballero y la divinidad, podría justificarse el acatamiento de 
este segundo aviso en el sentido de que, si don Quijote se asemejaba a Dios y actuaba en la búsqueda de su propia gloria, también obraba por la gloria de Dios, enfocado en sí mismo.

El tercero de los avisos regía que todos sus hermanos habían de poner "todas sus fuerzas en alcanzar la perfecta obediencia, sujetando sus voluntades y juicios a sus superiores" (Ribadeneyra, 1863: 355). A este respecto, Unamuno, pese a que jamás destacó por su respeto hacia las jerarquías, sí que hizo énfasis en el poder de la voluntad como fuerza mayor para conseguir cualquier propósito. Además, Sancho Panza sería un ejemplo de servidumbre, aunque una servidumbre a veces alabada por su obediencia y otras — quizá menos frecuentes - desdeñada al admirar al escudero por rebelarse contra su amo, como sería el caso del comentario unamuniano al capítulo LX de la primera parte del Quijote, cuando este se subleva contra los azotes salvadores de Dulcinea y tira a su señor al suelo por tratar de golpearlo: “[...] bien mirado, tampoco está del todo mal que Sancho se rebele así, pues de no haberse nunca rebelado no sería hombre, hombre de verdad" (VQS, p. 455). También nuestro autor elogió que don Quijote mostrase fe ciega en Dios, por ejemplo, en el episodio del capítulo XVII del segundo Quijote (Cervantes, 2008, II: 162-173), en que nuestro protagonista se enfrentó al león, pues “entendió la voluntad del Señor y obedeció según la tercera y más perfecta manera de obedecer que hay" (VQS, p. 370), ilustrando así su servidumbre en cuanto a sus deseos para con el mayor de los superiores.

El cuarto aviso insistía en que todos los creyentes buscasen lo mismo que buscó Jesucristo, esto es, "salvar las ánimas y padecer y morir en la cruz por ellas" (Ribadeneyra, 1863: 355), así como ofrecerse a recibir "cualquier afrenta e injuria que les hicieren por amor del Señor, con contento y regocijo de corazón, y deseando que se les hagan muchas" (Ribadeneyra, 1863: 355). Para Unamuno, don Quijote se presentó como el salvador del alma española, el mártir que sacrificó su cordura por la del pueblo español, "para dejarnos eterno ejemplo de generosidad espiritual" (VQS, p. 163); pero además, estas palabras recuerdan la escena en que los galeotes robaron y apedrearon al loco manchego y nuestro autor abogó por aquel ataque como el mayor halago que le podrían hacer, pues tomaron sus ropas, según él, como recuerdo y le lanzaron aquellas piedras "por agradecimiento también. Peor habría sido que le hubiesen vuelto la espalda" (VQS, p. 259-260). Sin embargo, siendo realistas, ni don Quijote ni Unamuno tendían a recibir demasiado bien las burlas que, según el juicio ignaciano, podrían considerarse afrentas que soportar por el honor de Dios.

A su vez, una nueva analogía, ciertamente menos reiterada, pero que también tuvo lugar, se observa entre san Ignacio y su constantemente atacado Cervantes a través de una carta que Miguel de Unamuno, desde Francia, envió a Jorge Luis Borges — su corresponsal en la revista Nosotros - el 26 de marzo de $1927^{5}$. En dicho texto, tal y como García Queipo transcribe, nuestro autor vinculó a Cervantes con san Ignacio de Loyola: "Sentí antaño la sonrisa triste de Cervantes inválido de guerra, manco de Lepanto — como Loyola_, inválido de guerra, cojo de Pamplona" (García Queipo de Llano, 1988: 313). Ese paralelismo también apareció un año antes en una carta que Unamuno escribió a Jean Cassou, así como en una publicación ${ }^{6}$ de Hojas Libres (1 de julio de 1927) y en su inacabado Manual de Quijotismo, entendiendo que, de

\footnotetext{
Correspondencia que sería publicada en el número 215 de la mencionada revista, Nosotros, en abril de aquel mismo año, pp. 126-127.

6 En el artículo “Orígenes de la cruzada”. Cito por Vauthier en Unamuno (2005: 100-101).
} 
sus lesiones, nacieron sus creaciones: "Cervantes soldado, manco en Lepanto, de su manquera. Q[uijote] — san Íñigo, soldado, cojo en Pamplona, de su cojera Compañía" (Unamuno, 2005: 100).

Resulta innegable que la Vida de San Ignacio de Loyola, escrita por Pedro de Ribadeneyra, tuvo una notable influencia sobre Miguel de Unamuno y su particular don Quijote de la Mancha. A juicio de nuestro escritor, el mayor triunfo del Caballero de la Triste Figura residía en el logro de convencer a sus adeptos para que lo siguieran en sus creencias, bien fuese por compartir su pensamiento - como era el caso de Sancho-, o bien para darle la razón a fin de evitar algún mal mayor, alguna disputa o para disuadirlo de regresar a su hogar - como hizo la gran mayoría de personajes con los que interactúa - . De cualquiera de las formas, el hidalgo manchego consiguió conmover los sentidos o, como el pensador bilbaíno explicaba en su comentario al capítulo XLIX de la Primera Parte del texto cervantino, su fuerza inspiradora era la que lograba un efecto sobre las personas, "cuando mueve a obrar a los hombres, encendiéndoles los corazones, o les consuela de la vida" (VQS, p. 319). Una expresión que podría antojarse bastante similar a la que ya Ribadeneyra ofreció sobre la labor ignaciana, cuyo cargo principal era el "de mover los corazones de los hombres a la virtud, y encender en ellos el fuego del amor divino" (Ribadeneyra, 1863: 171); o la forma en la que Dios actúa, tan quijotescamente según el juicio unamuniano, de hacer reaccionar los corazones para que puedan presenciar la realidad ideal: "Así suele nuestro Señor trocar los corazones a los que trae a su servicio y con la nueva luz que les da les hace ver las cosas como son, y no como primero les parecían" (44).

A través de estas palabras, tan similares a las que Unamuno usaría al referirse a su Cristo Hispánico, llegaríamos a una nueva conclusión, y es que no solamente el paralelismo entre su Caballero de la fe y el fundador de la Compañía de Jesús le permitía elevarlo como ejemplar figura a respetar dentro de la fe cristiana española, sino que daría un paso más, promoviendo su divinización a personaje identificable, no ya con Íñigo de Loyola, sino con el mismo Dios, cumpliendo ambos similar función de conmover los corazones y de despertar a los creyentes del mundo de las apariencias al paraíso de la idealidad: el paraíso de la salvadora locura quijotesca.

En última instancia, sería interesante señalar un apunte novedoso respecto a la influencia que san Ignacio ejerció sobre la escritura de Unamuno. Si nos remontásemos a su primera gran novela de finales del siglo XX, Paz en la guerra, es ya bien conocido que "la elección del nombre de Ignacio era intencionada por traer a la memoria de los vascos al heroico capitán de Loyola" (Gutiérrez, 1986: 269). El mismo Unamuno admitió en una Carta a Clarín, escrita desde Salamanca (2 de octubre de 1895), que había nombrado de esa forma a su personaje porque veía en él "toda el alma del pueblo vascongado" (Alas, 1941: 64). Sin embargo, en lo que respecta al título de esta novela histórica —o intrahistórica-, no se han encontrado referencias respecto a su vinculación con el santo o su biógrafo. Los estudios que aluden al nombre de la obra tienden a relacionarla con el libro de Tolstoi, La guerra y la paz, "cuyos títulos ya sugieren un cierto parentesco" (Oostendorp, 1967: 90). Y así, aunque Unamuno solía irritarse ante cualquier sugerencia que insinuase que se había visto influenciado por otras fuentes ${ }^{7}$, autores como Oostendorp afirmarían lo siguiente:

Cita perteneciente a una carta de Unamuno dirigida al poeta chileno Ernesto A. Guzmán, en que acusaba la búsqueda de influencias en su obra como un ataque contra su personalidad (Oostendorp, 1967: 88). 
A nosotros nos parece incuestionable el que el novelista español durante la redacción de Paz en la guerra se inspiró en la obra tolstoiana. Ya señalamos que el mismo título Paz en la guerra sugiere cierto parentesco con La guerra y la paz. Bien es verdad que Unamuno, unos meses antes de que saliera su libro a la luz pública, pensó en cambiarlo por $\mathrm{Paz}$, pero la expresión "paz en la guerra" se repite tantas veces en la obra y expresa tan maravillosamente el sentido de la misma, que no sería posible encontrar mejor título (Oostendorp, 1967: 104-105).

No obstante, si bien se confía en que haya quedado demostrada la insistente presencia que la Vida de San Ignacio de Loyola tuvo entre las lecturas de Unamuno y cómo esta lo motivó a escribir y fomentar parte de su filosofía quijotesca, no sería desacertado rebatir esta supuesta exclusividad del vínculo con Tolstoi y aportar una nueva sugerencia sobre la expresión con que titularía su Paz en la guerra; pues también es probable que Miguel de Unamuno tomase esta idea primaria a partir de las palabras del propio padre Ribadeneyra cuando, en el capítulo XVI del Libro I de la Vida de san Ignacio, abarcó los peligros ocasionados por el conflicto bélico entre España y Francia en el siglo XVI: "mas no bastaron todas estas cosas a detener el camino de Ignacio, que se sentía llevar del favorable viento del Espíritu Santo, y que hallaba paz en la guerra, y en los peligros seguridad, y en los trabajos descanso" (Ribadeneyra, 1863: 114).

Si bien a lo largo del artículo ha quedado establecido el recurrente paralelismo entre el Quijote reinterpretado de Miguel de Unamuno y la Vida de San Ignacio de Loyola, quizá esta última observación sobre la posible influencia existente tras el título de la novela Paz en la guerra ofrezca una nueva y diferente perspectiva en lo que al estudio de la misma se refiere.

\section{Obras citadas}

Aguilera, Emiliano M., "El padre Pedro de Ribadeneyra y su Vida de San Ignacio de Loyola. Notas prologales", en Pedro de Ribadeneyra, Vida de San Ignacio de Loyola, ed. Ignacio de Beyres, Barcelona, Obras Maestras, 1961, pp. vii-xii.

Alas, Adolfo (ed.), Epistolario a Clarín (Menéndez y Pelayo, Unamuno, Palacio Valdés), pról. y notas de Adolfo Alas, Madrid, Escorial, 1941.

Bucurenciu Birsan, Ileana, "Apuntes sobre el estilo de Unamuno en Vida de Don Quijote y Sancho", en AA.VV (eds.), Actas del Quinto Congreso Internacional de Hispanistas, I, Burdeos, Université, 1977, pp. 235-243.

Castelar, Emilio, La revolución religiosa, IV, Barcelona, Montaner y Simón, 1883.

Cervantes, Miguel de, El Ingenioso Hidalgo don Quijote de la Mancha, ed. John Jay Allen, Madrid, Cátedra, 2008, 2 vols.

Chevalier, Maxime, Lectura y lectores en la España del siglo XVI y XVII, Madrid, Turner, 1976.

Ferrater Mora, José, Unamuno. Bosquejo de una filosofía, Madrid, Alianza, 1985.

García Mateo, Rogelio, “Don Quijote de la Mancha e Íñigo de Loyola en Unamuno según la Vida de Don Quijote y Sancho", en José Ramón Fernández de Cano y Martín (ed.), CVC: Actas del VIII Coloquio Internacional de la Asociación de Cervantistas: [El Toboso, 2326 de abril de 1998], El Toboso, Ediciones Dulcinea del Toboso, 1999, pp. 127-141. 
García Queipo de Llano, Genoveva, Los intelectuales y la dictadura de Primo de Rivera, Madrid, Alianza, 1988.

González Caminero, Nemesio, Unamuno I. Trayectoria de su ideología y de su crisis religiosa, Comillas, Universidad Pontificia, 1948.

Gutiérrez, Jesús, "Unamuno entre la épica y la intrahistoria: Relectura de Paz en la guerra", en Actas del IX Congreso de la Asociación Internacional de Hispanistas 18-23 agosto 1986, II, Berlín, Frankfurt am Main, Vervuert, 1989, pp. 265-274.

Iglesias Ortega, Luis, El quijotismo de Unamuno. Entre la filosofía y el mito, Madrid, Universidad Complutense, 1990.

Iparraguirre, Ignacio, y Cándido de Dalmases, “Introducción”, en Ignacio de Loyola, Obras completas, ed. Cándido Dalmases, transcripción, introducciones y notas de Ignacio Iparraguirre, Madrid, Editorial Católica, 1982, pp. 1-58.

Machado, Antonio, Antología poética, Madrid, Salvat y Alianza, 1969.

—, "Divagaciones", en A. Sánchez Barbudo (ed.), Miguel de Unamuno, Madrid, Taurus, 1990, pp. 91-92.

Menéndez Pelayo, Marcelino, Historia de las ideas estéticas en España, I, Madrid, CSIC, 1994.

Montero Díaz, Santiago, Cervantes, compañero eterno, Ourense, Linteo, 2005.

Montesinos, José, "Muerte y vida de Unamuno", en A. Sánchez Barbudo, ed., Miguel de Unamuno, Madrid, Taurus, 1990, pp. 23-33.

Morón Arroyo, Ciriaco, “'Alma nacional'. El transfondo sociológico de En torno al casticismo", en Theodor Berchem y Hugo Laitenberger (eds.), El joven Unamuno en su época, Salamanca, Junta de Castilla y León, 1997, pp. 11-30.

Navarro, Alberto, "Nuestra edición”, en Miguel de Unamuno, Vida de Don Quijote y Sancho, Madrid, Cátedra, 1992, pp. 116-123.

Oostendorp, Herre, "Los puntos de semejanza entre La Guerra y la Paz de Tolstoi y Paz en la guerra de Unamuno", Bulletin Hispanique, 69.1-2 (1967), pp. 85-105.

Porqueras Mayo, Alberto, Estudios sobre Cervantes y la Edad de Oro, Madrid, Centro de Estudios Cervantinos, 2003.

Ribadeneyra, Pedro de, Vida de San Ignacio de Loyola Fundador de la Religión de la Compañia de Jesús, Barcelona, Librería de la Viuda e Hijos de J. Subirana, editores, 1863.

—, Vida de San Ignacio de Loyola, ed. Ignacio de Beryes, Barcelona, Obras Maestras, 1961.

Unamuno, Miguel de, "La Educación Jesuítica", Repertorio Americano, 24 (1921), pp. 234236.

—, Mi vida y otros recuerdos personales, II, Buenos Aires, Losada, 1959.

—, El Caballero de la Triste Figura, $5^{\text {a }}$ ed., Madrid, Espasa Calpe, 1970.

—, Vida de Don Quijote y Sancho, ed. Alberto Navarro, Madrid, Cátedra, 1992.

-, Obras completas, IV. Poesías. Rosario de sonetos líricos. El Cristo de Velázquez. Rimas de dentro. Teresa. De Fuerteventura a París. Romancero del destierro, ed. Ricardo Senabre, Madrid, Fundación José Antonio de Castro, 1999.

-, Manual de Quijotismo. Cómo se hace una novela. Epistolario Miguel de Unamuno / Jean Cassou, pról. Bénedicte Vauthier, Salamanca, Universidad, 2005.

—, Obras Completas, VIII. Ensayos, ed. Ricardo Senabre, Madrid, Biblioteca Castro, 2007. 